
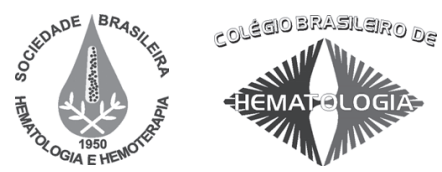

\title{
O transplante de células-tronco hematopoéticas na infância: situação atual e perspectivas
}

\author{
Hematopoietic stem cell transplantation in childhood: current status and perspectives
}

O transplante de células-tronco hematopoéticas (TCTH) é uma opção terapêutica para um grande número de crianças com doenças malignas e não malignas. O objetivo deste artigo é apresentar a situação atual dos TCTH em pediatria para o tratamento de doenças hematológicas malignas, incluindo dados de nosso país e perspectivas futuras. Rev. Bras. Hematol. Hemoter. 2009;31(Supl. 1):59-67.

Palavras-chave: Transplante de medula óssea; transplante de células-tronco periféricas; pediatria; leucemia.

\section{Introdução}

O transplante de células-tronco hematopoéticas (TCTH) é uma opção terapêutica para um grande número de crianças com doenças malignas e não malignas. Em outros artigos deste suplemento o leitor encontrará revisão sobre a caracterização das células-tronco, histórico e aspectos gerais dos TCTH, vantagens e desvantagens da utilização do sangue de cordão umbilical e aplicações dos TCTH no tratamento de doenças não-hematológicas.

Assim, o objetivo deste artigo é apresentar a situação atual dos TCTH em pediatria para o tratamento de doenças hematológicas malignas, incluindo dados de nosso país e perspectivas futuras.

Um dos aspectos mais importantes em discussões sobre os transplantes é o fato de não existirem indicações absolutas: o TCTH é uma das opções terapêuticas disponíveis para um grande número de doenças. A sua indicação será sempre correta se a sobrevida global e qualidade de vida forem significantemente melhores com o transplante do que com tratamento convencional, em geral quimioterápico. As indicações dos transplantes devem ser, portanto, periodicamente reavaliadas no decorrer do tempo, levando em conta os avanços científicos em ambas as áreas para que possamos sempre apresentar aos pacientes, baseados em evidên- cias, as melhores opções terapêuticas para cada doença.

Uma das grandes dificuldades para atingir esta meta em nosso meio é a ausência de publicação sistemática de resultados obtidos com protocolos convencionais ou com TCTH e escassez, na literatura mundial, de estudos randomizados que comparem diretamente tratamento convencional versus TCTH nas diversas situações clínicas. Na prática, muitas das indicações de TCTH fundamentam-se em resultados ruins obtidos com quimioterapia e relativamente melhores quando são relatados os pacientes transplantados. Entretanto, quando não é feita randomização, pode existir um importante viés na comparação, pois nem todos os pacientes chegam a ser elegíveis para o transplante: crianças com doença mais agressiva, com resposta ruim à quimioterapia, em más condições clínicas gerais ou sem doador HLA-compatível são incluídas somente no grupo de tratamento convencional, selecionando-se, para o grupo de transplante, pacientes de melhor prognóstico e influenciando os resultados observados em levantamentos retrospectivos.

Mais de 500 centros de transplante em 54 países relatam os dados de todos os transplantes que realizam ao CIBMTR (Center for International Blood and Marrow Transplant Research"), constituindo uma das principais fontes de consulta sobre os resultados obtidos nos dias atuais. $^{2}$

Pediatra. Chefe do Centro de Transplante de Medula Óssea do Instituto de Oncologia Pediátrica - GRAACC - Unifesp - São Paulo-SP.

Instituto de Oncologia Pediátrica - GRAACC - Unifesp - São Paulo-SP.

Correspondência: Adriana Seber

Rua Botucatu, 743

04023-062 - São Paulo-SP - Brasil

E-mail: adrianaseber@graacc.org.br

Doi: 10.1590/S1516-84842009005000035 
No Brasil, todos os centros de TCTH foram convidados a participar de levantamento retrospectivo realizado pelo Comitê de Transplante de Medula Óssea em Pediatria da Sociedade Brasileira de Oncologia Pediátrica (Sobope) e Sociedade Brasileira de Transplante de Medula Óssea (SBTMO). Vinte instituições relataram os resultados de 1.149 transplantes realizados em pacientes com menos de 19 anos entre março/ 1985 e dezembro/2007. Os resultados deste trabalho, apresentados no XII Congresso da SBTMO em setembro/2008, servirão como referência para os resultados de TMO em pediatria no nosso país. ${ }^{3-10}$

Estima-se que sejam realizados em todo o mundo entre 50 mil e 60 mil transplantes a cada ano. A fonte de células-tronco hematopoéticas mais utilizada em transplantes alogênicos aparentados em crianças é a medula óssea (54\%), seguido do sangue periférico (27\%) e do sangue de cordão umbilical (19\%), em contraste com transplantes em adultos, que utilizam principalmente o sangue periférico. $^{2}$

Considerando-se apenas os transplantes autólogos, o sangue periférico é utilizado em $90 \%$ dos casos, seguido da medula óssea; há raríssimos relatos de utilização de sangue de cordão autólogo. Como o dano genético que leva ao aparecimento das leucemias na infância pode ocorrer já na vida intrauterina, ${ }^{11-13} \mathrm{o}$ desenvolvimento de leucemia na infância é razão imperativa para não ser utilizado um sangue de cordão que tenha sido criopreservado e doado para uso nãoaparentado ou mantido para uso familiar. Ou seja, o sangue de cordão da própria criança não é uma boa fonte de célulastronco caso ela venha a desenvolver leucemia.

As células-tronco hematopoéticas só são coletadas do paciente no momento em que alcança a remissão completa com a quimioterapia. As células podem ser mantidas criopreservadas por vários anos, até o momento do transplante. O único efeito antitumoral advém dos quimioterápicos. A contaminação da medula ou do sangue periférico por células tumorais, mesmo em quantidades mínimas, pode contribuir para a recidiva do tumor, como há muitos anos foi demonstrado em crianças com leucemia mielóide aguda e neuroblastoma. ${ }^{14}$ Existem algumas técnicas disponíveis para o tratamento das células-tronco no laboratório (purging) para reduzir a chance de contaminação tumoral, mas, além de muito caras, nenhuma tem impacto comprovado na chance de cura dos pacientes. Os transplantes autólogos têm chance de morte devido ao procedimento entre $2 \%$ e $10 \%$.

Nos transplantes alogênicos em pediatria, a medula óssea é a principal fonte de células-tronco hematopoéticas, pois foi observada maior mortalidade associada ao transplante com o uso de células-tronco periféricas, ${ }^{15}$ além da questão ética da segurança de administrar fatores de cres- cimento a irmãos de crianças com câncer e de submetê-los à inserção de cateter venoso central e ao procedimento de leucoaférese.

Os transplantes alogênicos são tradicionalmente indicados para o tratamento de doenças com chance de cura inferior a 50\% com tratamento convencional, que são sensíveis ao escalonamento da dose de quimioterapia e/ou à ação dos linfócitos-T do doador (efeito do enxerto contra o tumor). ${ }^{16}$ As principais indicações de TCTH em doenças hematológicas malignas pediátricas estão listadas na Tabela 1.

Transplantes alogênicos dependem da disponibilidade de um doador HLA-compatível familiar ou não-aparentado. No Brasil, os doadores mais utilizados são os irmãos com HLA idêntico ao do paciente. No exterior, metade dos transplantes alogênicos utiliza doadores não-aparentados, também com HLA-idêntico. ${ }^{2}$

Entre pacientes com menos de 20 anos, metade dos transplantes alogênicos relatados ao CIBMTR já utiliza doadores não-aparentados, sendo medula óssea e sangue de cordão umbilical/placentário as fontes de células-tronco hematopoéticas mais utilizadas. ${ }^{2}$ No Brasil, $16 \%$ dos 774 transplantes alogênicos levantados pelo Comitê de TMO em pediatria foram não-aparentados. ${ }^{3}$

O uso crescente do sangue de cordão como fonte de células-tronco para o transplante está ampliando a possibilidade de transplantes não-aparentados para as nossas crianças: doadores adultos necessitam de compatibilidade de todos os antígenos HLA, mas transplantes de cordão têm bons resultados com até dois antígenos HLA diferentes entre o doador (unidade) e o paciente. ${ }^{17} \mathrm{O}$ sangue de cordão já é utilizado em $40 \%$ dos transplantes não-aparentados pediátricos no exterior ${ }^{2}$ e $67 \%$ dos transplantes não-aparentados realizados no Brasil. ${ }^{4}$

$\mathrm{Na}$ seleção de doadores não-aparentados adultos, a análise retrospectiva de centenas de pacientes já transplantados demonstrou que a tipagem HLA convencional, baseada em resultados de sorologia ou técnicas moleculares de resolução intermediária, não é suficiente para a seleção de 
doadores não-aparentados adultos: para estes casos, é necessária a compatibilidade a nível molecular ou em "alta resolução", tanto em classe I (antígenos A, B e C) quanto em classe II (antígenos DR, DP, DQ). ${ }^{18-21}$

Em grandes centros, a seleção cuidadosa de doadores não-aparentados foi um dos fatores que possibilitou a melhoria progressiva dos resultados dos transplantes, hoje comparáveis aos obtidos com transplantes entre irmãos HLAcompatíveis. ${ }^{22}$ A legislação brasileira (Portaria No 2.041 de 25 de setembro de 2008) já permite a tipagem HLA de classe I por testes moleculares de média/alta resolução, obedecendo aos avanços científicos, mas necessitamos ainda de adequação da infraestrutura de nossos laboratórios para realizar estes exames rotineiramente.

As principais causas de falha dos transplantes são recidiva da doença maligna, doença do enxerto contra o hospedeiro, infecções e toxicidade do regime preparatório. ${ }^{23} \mathrm{~A}$ toxicidade associada ao procedimento do TCTH é geralmente quantificada através da chance de óbito nos primeiros cem dias após o transplante ou "mortalidade associada ao transplante" (MAT). A mortalidade varia com a idade, diagnóstico e fase da doença ao transplante, sendo menor em jovens, submetidos a transplante autólogo, com doença quimiossensível em fase inicial. Nos transplantes alogênicos aparentados para tratamento de leucemia mielóide aguda, por exemplo, a MAT é de até $10 \%$ para pacientes em remissão e maior que $20 \%$ com doença em atividade. ${ }^{23} \mathrm{Em}$ transplantes nãoaparentados, a mortalidade é habitualmente o dobro da observada em transplantes com irmãos HLA compatíveis. No Brasil, a mortalidade associada aos transplantes aparentados foi de $20 \%$ e aos não-aparentados foi de $39 \%$, associada principalmente a infecções, recidiva, falha de pega e doença do enxerto contra o hospedeiro. ${ }^{4}$
Os resultados dos transplantes em pacientes com menos de 20 anos relatados ao CIBMTR estão descritos na Tabela 2. Devido à grande incidência em pediatria, as leucemias agudas são os diagnósticos mais frequentes entre as crianças transplantadas. Na leucemia linfóide aguda (LLA), assim como em outras doenças malignas, o grupo considerado como de alto risco é aquele para o qual se espera uma sobrevida livre de eventos inferior a 50\% apesar de tratamento quimioterápico apropriado. ${ }^{16}$ As crianças que se enquadram nesta categoria de alto risco são as que têm o diagnóstico de LLA e um ou mais fatores de risco, como BCR/ABL $[\mathrm{t}(9 ; 22)]$, MLL [t( $4 ; 11)]$, menos de 44 cromossomas e resposta inadequada ao tratamento (Tabela 3 ). Outros fatores também podem estar associados à apresentação mais agressiva da doença, mas não têm, isoladamente, prognósticos tão reservados: imunofenótipo $\mathrm{T}, \mathrm{t}(1 ; 19)$, envolvimento do sistema nervoso central e/ou liquórico e/ou acidente na punção liquórica ao diagnóstico, hiperleucocitose maior que 50 x 10(9)/ $\mathrm{L}$, idade maior que 10 anos ou menor que 1 ano.

Nas duas últimas décadas, vários grupos cooperativos dedicaram-se a avaliar o impacto da presença de doença residual mínima durante o tratamento da LLA e definir, assim, grupos de bom e de mau prognóstico (Tabela 4). Os métodos mais utilizados são a imunofenotipagem e as alterações moleculares específicas. Estes testes são de execução relativamente simples, mas a análise dos resultados é complexa. Assim, a quantificação de doença residual mínima só deve ser utilizada se estiver clinicamente validada como fator prognóstico no protocolo utilizado pelo serviço e se forem tomadas medidas rigorosas de controle de qualidade. ${ }^{16}$

Em todos os estudos de recidiva de LLA, o prognóstico é tanto pior quanto menor a duração da primeira remissão. O grupo BFM classifica a recidiva em muito precoce (menos

Tabela 2. Sobrevida global em três anos de pacientes com menos de 20 anos submetidos

a transplante de células-tronco hematopoéticas e relatados ao Center for International Blood and Marrow Transplantation Research (CIBMTR)

\begin{tabular}{lccc}
\hline \multicolumn{1}{c}{ Diagnóstico } & Aparentado & Não aparentado & Autólogo \\
\hline Leucemia linfoide aguda & $\mathrm{N}=2068$ & $\mathrm{~N}=2636$ & $\mathrm{NA}$ \\
$-1^{\text {a } \text { remissão }}$ & $62 \%$ & $56 \%$ & \\
$-\geq 2^{\mathrm{a}}$ remissão & $54 \%$ & $42 \%$ & \\
- Falha indutória/ doença ativa & $27 \%$ & & $\mathrm{~N}=282$ \\
& & $*$ & $62 \%$ \\
Leucemia mieloide aguda & $\mathrm{N}=1422$ & & $57 \%$ \\
- 1a remissão & $65 \%$ & & \\
- $\geq 2^{\mathrm{a}}$ remissão & $57 \%$ & & \\
- Falha indutória/ doença ativa & $35 \%$ & $\mathrm{~N}=316$ & \\
Síndrome mielodisplásica & $\mathrm{N}=169$ & $60 \%$ & \\
- Anemia refratária (AR) & $62 \%$ & $48 \%$ & \\
- AR com excesso de blastos & $59 \%$ & & \\
\hline
\end{tabular}

* sem dados referentes a pacientes com menos de 20 anos. Adaptado de Pasquini MC, Wang Z. Current use and outcome of hematopoietic stem cell transplantation: part II- CIBMTR summary slides, 2007. CIBMTR Newsletter [serial online]. 2008;14(1):6-13. Disponível em: http://www.cibmtr.org/PUBLICATIONS/Newsletter/index.html. Acesso em 31/10/2008 
Tabela 3. Características de leucemia linfóide aguda pediátrica que

determinam tratamento em grupos de alto risco

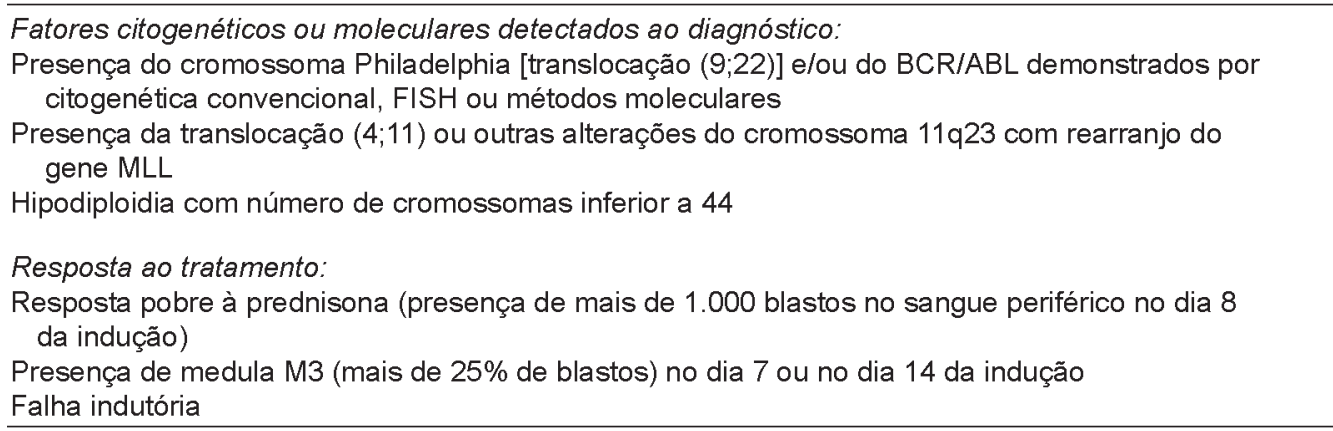

Adaptado de Schrappe M. Radiation Protection Dosimetry 2008; 132 (2):130-316

Tabela 4. Indicações de transplante de células-tronco hematopoéticas em leucemia linfóide aguda na infância em primeira remissão, segundo os critérios do grupo Berlin-Frankfurt-Munster (BFM)

\begin{tabular}{|c|c|}
\hline Critério de alto risco & Indicação de transplante \\
\hline $\begin{array}{l}\text { Ausência de remissão no D33 } \\
\text { Presença de DRM } \geq 10^{-2} \text { na semana } 12 \\
\text { Presença de DRM } \geq 10^{-3} \text { na semana } 12\end{array}$ & $\begin{array}{l}\text { Sempre, qualquer doador } \\
\text { Sempre, qualquer doador } \\
\text { Doador irmão ou compatível ou qualquer doador se ausência } \\
\text { de remissão no D33 ou t }(9 ; 22) \text { e resposta pobre à prednisona* }\end{array}$ \\
\hline $\begin{array}{l}\text { Resposta pobre à prednisona e } t(9 ; 22) \\
\text { Resposta pobre à prednisona e } t(4 ; 11) \\
\text { Boa resposta à prednisona e } t(9 ; 22)\end{array}$ & $\begin{array}{l}\text { Sempre, qualquer doador } \\
\text { Doador irmão ou compatível } \\
\text { Doador irmão ou compatível } \\
\text { Não indicar se DRM }<10^{-4} \text { nas semanas } 4 \text { e } 12^{*}\end{array}$ \\
\hline $\begin{array}{l}\text { Boa resposta à prednisona e } \mathrm{t}(4 ; 11) \\
\text { Resposta pobre à prednisona } \\
\text { Boa resposta à prednisona }\end{array}$ & $\begin{array}{l}\text { Doador irmão* } \\
* \\
*\end{array}$ \\
\hline
\end{tabular}

Qualquer doador: irmão HLA-idêntico ou doador aparentado ou doador não aparentado com HLA idêntico ou parcialmente compatível. DRM: doença residual mínima avaliada na semana 12 da indução. *: caso paciente apresente DRM na semana 12, este critério de indicação deve prevalecer. Pacientes sem avaliação de DRM: adotar conduta conservadora, comose resultado de DRM fosse negativo. Doador irmão: irmão HLA-idêntico. Doador compativel: familiar compatível em todos os 10 alelos HLA tipados em alta resolução (A, B, C, DRB1, DQB1), doador não aparentado $\geq 9 / 10$, irmão 9/10. HLA parcialmente compatível: <9/10. Adaptado de: Schrauder A, von Stackelberg A, Schrappe M, Cornish J, Peters ALL-BFM Study Group; EBMT PD WP; I-BFM Study Group. Allogeneic hematopoietic SCT in children with ALL: current concepts of ongoing prospective SCT trials. Bone Marrow Transplant, 2008; 41 Suppl 2: S71-4. ${ }^{1}$

de 18 meses após o diagnóstico), precoce (entre 18 meses do diagnóstico e 6 meses após o término da manutenção) e tardia (mais de seis meses após o fím de tratamento). ${ }^{24} \mathrm{O}$ pior prognóstico foi observado nas recidivas precoces ou muito precoces medulares, isoladas ou combinadas: menos de $20 \%$ de sobrevida global em dez anos. O transplante alogênico em segunda remissão proporcionou sobrevida livre de eventos em dez anos de $55 \%$, comparado com $33 \%$ com quimioterapia ( $22 \% \mathrm{em}$ pacientes com recidiva medular isolada). No Brasil, $44 \%$ dos 231 transplantes para tratamento de LLA em pediatria foram realizados em fases bastante avançadas da doença, a partir da segunda recidiva ou com remissão parcial, o que está associado a alta MAT (28\%). ${ }^{6}$ A sobrevida global em cinco anos de pacientes em primeira ou segunda remissão foi de $38 \%$, comparado com $21 \%$ em fases avançadas.
Embora não existam trabalhos randomizados, o transplante é uma das opções terapêuticas para LLA em segunda remissão, levando-se sempre em consideração o momento (precoce $v s$. tardia) e local da recidiva (medular, combinada, extramedular) e do tipo de doador disponível para o paciente, como apresentado na Tabela 5. Transplantes com doador irmão HLA-idêntico têm baixo risco de óbito pelo procedimento e podem ser indicados na maior parte das situações de recidiva. Transplantes não-aparentado com HLA-idêntico a nível molecular têm bons resultados mas, em geral, só proporcionam melhor sobrevida global para pacientes com doença de alto risco, como recidivas medulares de LLA-T, recidivas medulares precoces isoladas ou muito precoces combinadas. ${ }^{25}$ Por outro lado, transplantes com incompatibilidade HLA estão associa- 
Tabela 5. Indicações de transplante de células-tronco hematopoéticas em leucemia linfóide aguda na infância em segunda remissão, segundo os critérios do grupo Berlin-Frankfurt-Munster (BFM)

\begin{tabular}{|c|c|}
\hline Recidiva & Transplantes indicados \\
\hline $\begin{array}{l}\text { Alto risco: } \\
\text { - Todas as recidivas de LLA-T }\end{array}$ & Sempre, qualquer doador \\
\hline \multicolumn{2}{|l|}{$\begin{array}{l}\text { Em LLA-linhagem B, recidiva: } \\
\text { - Medular }<18 \text { meses do diagnóstico } \\
\text { - Medular isolada }<6 \text { meses após o fim do tratamento }\end{array}$} \\
\hline $\begin{array}{l}\text { Risco intermediário } \\
\text { - Combinada }<6 \text { meses após fim do tratamento } \\
\text { - Medular }>6 \text { meses após fim do tratamento } \\
\text { se houver blastos no sangue periférico* ou se } D R M \geq 10^{-3}\end{array}$ & Doador compatível \\
\hline $\begin{array}{l}\text { Risco intermediário } \\
\text { - Medular }>6 \text { meses após fim do tratamento e ausência de } \\
\text { blastos no sangue periférico ou } \mathrm{DRM}<10^{-3}\end{array}$ & Doador irmão \\
\hline $\begin{array}{l}\text { Risco intermediário } \\
\text { - Combinada ou medular }>6 \text { meses após fim do tratamento e } \\
\text { ausência de blastos no sangue periférico ou } \mathrm{DRM}<10^{-3}\end{array}$ & Não transplantar \\
\hline \multicolumn{2}{|c|}{$\begin{array}{l}\text { A presença de blastos no sangue periérico é avaliada no momento da recidiva.A presença de doença residual } \\
\text { mínima, determinada por técnicas moleculares, é avaliada após segundo bloco de induç } \\
\text { Adaptado de Schrauder A, von Stackelberg A, Schrappe M, Cornish J, Peters C; ALL-BFM Study Group; EBMT } \\
\text { PD WP; I-BFM Study Group. Allogeneic hematopoietic SCT in children with ALL: current concepts of ongoing } \\
\text { prospective SCT trials. Bone marrow transplant, 2008; } 41 \text { Suppl 2: S71-4. }{ }^{1}\end{array}$} \\
\hline
\end{tabular}

dos a alta morbi-mortalidade, sendo reservados para os casos muito graves.

Mesmo que esteja planejado o transplante, a intensidade da quimioterapia de resgate e a qualidade da segunda remissão são fundamentais para os bons resultados a longo prazo. O grupo BFM estudou prospectivamente o impacto da doença residual mínima em 91 crianças submetidas ao TCTH a partir da segunda remissão. Crianças em remissão medular à microscopia ótica, com mais de $10^{-4}$ blastos, segundo técnicas moleculares, tiveram sobrevida livre de eventos em cinco anos de $57 \%$ e recidiva após TCTH de $13 \%$; com doença residual inferior a $10^{-4}$, a sobrevida passou para $27 \%$ e recidiva para $60 \%{ }^{26}$

Na leucemia mielóide aguda (LMA) pediátrica, vários protocolos compararam o tratamento quimioterápico exclusivo com transplante autólogo e transplante alogênico e existe muita controvérsia na interpretação dos resultados. Transplantes autólogos na primeira remissão de LMA em pediatria têm resultados inferiores aos obtidos com tratamento quimioterápico e foram, por isso, abandonados pela maior parte dos grupos há vários anos. $\mathrm{O}$ melhor tratamento antileucêmico é, sem dúvida, o transplante alogênico, ou seja, o TCTH de doador irmão HLA-compatível proporciona a maior sobrevida livre de doença na LMA em pediatria. Entretanto, o aumento da sobrevida global é inferior a 10\% em diversos trabalhos cooperativos, pois crianças em remissão podem falecer por toxicidade associada ao transplante e pacientes que apresentam recidiva da doença após o tratamento quimioterápico podem ser resgatados com TCTH em segunda remissão. ${ }^{27}$
$\mathrm{Na}$ opinião dos grupos norte-americanos, como o Childrens Oncology Group, todos os pacientes com LMA e doador irmão HLA-idêntico disponível, exceto os com leucemia promielocítica, deveriam ser submetidos a transplante alogênico aparentado em primeira remissão, mesmo levando-se em conta o pequeno benefício em termos de sobrevida global. ${ }^{28}$ Segundo a opinião do Grupo Europeu de Transplante de Medula Óssea (EBMT - Paediatric Diseases Working Party), os TCTH só deveriam ser realizados em primeira remissão em pacientes com doença de alto risco, como, por exemplo, leucemia secundária, morfologia FAB M0, M6, M7 em pacientes não Down, monossomia do cromossoma 7, duplicação interna em tandem do gene FLT-3, ou presença de mais de $15 \%$ de blastos na medula após a primeira indução (Tabela 6). ${ }^{29,30}$

Em segunda remissão, embora não haja estudos comparando prospectivamente quimioterapia e TCTH, o transplante alogênico é geralmente recomendado devido aos maus resultados obtidos com quimioterapia, especialmente no caso de recidivas precoces (remissão com duração inferior a um ano).

A leucemia mielóide promielocítica é, provavelmente, a única condição de LMA pediátrica em que o transplante autólogo em segunda remissão pode ter benefício em relação ao alogênico aparentado ou não-aparentado: pacientes que atingem remissão molecular com o trióxido de arsênico e depois realizam o TCTH em segunda remissão têm excelente chance de cura. Na LMA-M3, portanto, o transplante alogênico só é habitualmente indicado àqueles que não alcançam remissão medular molecular. ${ }^{29}$ Pacientes portadores 
Tabela 6. Indicações de transplante de células-tronco hematopoéticas em neoplasias mieloides na infância

Considerar fortemente

1. LMA em $2^{a}$ remissão

2. SMD - anemia refratária com excesso de blastos

3. LMA com falha indutória em doença refratária

4. LMMJ

5. LMC (inibidores da tirosina cinase)

6. LMA secundária

Opção terapêutica - considerar 1. LMA com risco intermediário em $1^{\text {a }}$ remissão e
doador familiar HLA-idêntico

2. LMA de alto risco em $1^{\text {a }}$ remissão

Contraindicação relativa

1. LMA de baixo risco em $1^{\text {a }}$ remissão

2. LMA-M3 em $1^{\text {a }}$ remissão

LMA: Leucemia mieloide aguda. SMD: Síndrome mielodisplásica. LMMJ: Leucemia mielomonocítica juvenil. LMC: Leucemia mieloide crônica. HLA: antígeno maior de compatibilidade. LMA-M3: Leucemia mielóide aguda promielocítica

Adaptado de Shenoy S, Smith FO. Hematopoietic stem cell transplantation for childhood malignancies of myeloid origin. Bone marrow transplant, 2008; 41(2):141-829

da Síndrome de Down e LMA também têm bom prognóstico com protocolos quimioterápicos específicos, tendo indicação de TCTH somente se há recidiva da doença.

As síndromes mielodisplásicas na infância têm apresentação clínica muito distinta da observada nos adultos. Anormalidades constitucionais como mitocondriopatias (por exemplo a Síndrome de Pearson, associada à anemia refratária com excesso de blastos e sideroblastos em anel) e anemia de Fanconi podem estar presentes em até 20\% dos casos e precisam ser descartadas antes do transplante, pois determinam estratégias de tratamento completamente distintas. $^{31}$

Em crianças, a chance de evolução da mielodisplasia para formas mais avançadas e LMA é maior do que em adultos; quando ocorre, a indicação de quimioterapia é bastante discutível, pois a chance de alcançar remissão completa é muito pequena. Nos 58 transplantes relatados ao Comitê de Transplante de Medula Óssea em Pediatria da Sobope/ SBTMO, a sobrevida global em dois anos após TCTH para síndrome mielodisplásica foi de $64 \%{ }^{8}$

A leucemia mielomonocítica juvenil, uma forma muito agressiva de SMD/síndrome mieloproliferativa, vem sendo estudada pelo Grupo Europeu de Síndrome Mielodisplásica na Infância (European Working Group on Childhood Myelodysplastic Syndrome; European Blood and Marrow Transplantation Group). ${ }^{32}$ Os resultados dos transplantes nesta doença dependem da utilização de esquemas de condicionamento eficazes, como a associação de bussulfano, ciclofosfamida e melfalano e do efeito do enxerto contra a leucemia, já que recidiva da doença ainda é a principal causa de falha terapêutica.

A leucemia mielóide crônica (LMC) é uma doença relativamente rara em crianças e não sabemos quais serão, a longo prazo, os resultados do uso dos inibidores da tirosina quinase. Os transplantes alogênicos para LMC relatados ao
Comitê da Sobope/SBTMO tiveram mortalidade de $23 \%$ nos primeiros cem dias, sobrevida global em cinco anos de $78 \%$ na primeira fase crônica e de $37 \%$ em fases avançadas. Assim, os TCTH são, sem dúvida, uma das opções de tratamento da LMC em pediatria, mas não saberemos ainda, por muitos anos, se oferecem vantagens ou desvantagens em relação ao uso de inibidores da tirosina quinase. ${ }^{9}$

Linfomas são a principal indicação de transplante autólogo no tratamento de doenças hematológicas pediátricas. Cento e vinte nove pacientes foram relatados ao Comitê de TMO em Pediatria da Sobope/ SBTMO: um terço apresentou recidiva da doença e $64 \%$ estavam vivos com mediana de acompanhamento de três anos. ${ }^{10}$ A resposta à terapia e a duração da primeira remissão são fatores determinantes para o prognóstico após o transplante.. ${ }^{33}$ Como os linfomas não-Hodgkin e linfomas de Hodgkin são doenças predominantemente de adultos, crianças são geralmente incluídas nos mesmos protocolos de tratamento.

Linfomas de Burkitt, por outro lado, predominam na infância, são extremamente agressivos, com excelente resposta à quimioterapia. Na recidiva da doença está indicado o transplante autólogo, ${ }^{34}$ mas muitas vezes há refratariedade à quimioterapia. A associação de anticorpos monoclonais anti-CD20 à quimioterapia tem, aparentemente, aumentado o número de crianças que conseguem obter resposta completa e chegar ao TCTH. O uso de anticorpos monoclonais após o transplante vem sendo recomendado por alguns autores, mas não existem trabalhos randomizados que provem a sua eficácia.

Sabemos há muitos anos que algumas doenças são particularmente sensíveis ao efeito do enxerto contra o tumor, como por exemplo a LMC: a maior parte dos pacientes com recidiva após transplante alogênico alcança remissão recebendo exclusivamente infusão de leucócitos do mesmo doador (donor leukocyte infusion - DLI). Este potente efeito do enxerto contra o tumor contrapõe-se ao conceito que perdurou por muitas décadas, de que transplantes alogênicos só seriam possíveis após a completa destruição da hematopoese do paciente, ou seja, com regimes "mieloablativos." Assim, vários regimes de condicionamento vêm sendo desenvolvidos nos últimos anos com o intuito de imunossuprimir o receptor, ou seja, destruir seus linfócitos T, impedindo que rejeite as células hematopoéticas do doador. Os linfócitos do doador têm ainda efeito contra a hematopoese do receptor, permitindo a pega das células-tronco hematopoéticas. Esta nova modalidade de transplante é conhecida como "transplante de intensidade reduzida" (ou transplante não-mieloablativo, ou minitransplante). O CIBMTR define o 
regime de condicionamento como não-mieloablativo ${ }^{2}$ quando utiliza irradiação corporal total em doses $<500$ cGy em uma única fração ou $<800 \mathrm{cGy}$ fracionados, bussulfano $\leq 9 \mathrm{mg} / \mathrm{kg}$ ou melfalano $\leq 150 \mathrm{mg} / \mathrm{m}^{2}$.

Embora os regimes de intensidade reduzida sejam utilizados em $40 \%$ dos transplantes em adultos, são reservados para raros casos pediátricos em que há grave disfunção orgânica, mas para os quais a equipe de saúde opta por ainda assim oferecer o TCTH. Transplantes de intensidade reduzida permitem diminuição importante na mortalidade associada ao transplante a curto prazo, mas estão associados à toxicidade tardia pela imunossupressão intensa e à maior chance de recidiva de doenças avançadas. Seu papel futuro nos transplantes pediátricos provavelmente será no tratamento de doenças não malignas, como imunodeficiências, hemoglobinopatias ou, ainda, terá o intuito de estabelecer tolerância às células do doador, já que o quimeirismo misto torna possível o tratamento com populações celulares específicas ou mesmo transplante de órgãos sólidos do doador. ${ }^{35}$

Nas últimas décadas, o prognóstico dos pacientes submetidos a transplantes alogênicos aparentados e autólogos vem melhorando principalmente devido à melhoria no tratamento de suporte e consequente redução da mortalidade associada ao procedimento. Entretanto, a recidiva da doença maligna permanece a mais importante causa de falha do tratamento. A utilização de infusão de leucócitos do doador, que revolucionou a terapêutica da recidiva de LMC após o transplante, não teve impacto no tratamento de crianças. A melhor estratégia na pediatria ainda é diagnóstico precoce ou prevenção da recidiva através da avaliação rigorosa, sensível e frequente da doença residual mínima e do quimeirismo após os transplantes.

Entre os transplantes de doadores alternativos temos vivenciado enormes progressos na utilização de outras fontes de células-tronco para TCTH, como o sangue de cordão umbilical, na seleção de doadores e nas técnicas para possibilitar transplantes haploidênticos. Como os transplantes de cordão podem ser realizados com compatibilidade de apenas quatro dos seis principais antígenos HLA (A, B, DR), houve grande expansão do pool de doadores não aparentados. Mesmo em nosso meio, são raras, hoje, as crianças para as quais não se identifica um doador não aparentado. Assim, a nossa maior limitação passou a ser a disponibilidade de leitos especializados e recursos adequados para a realização dos transplantes não aparentados e não a identificação de um doador.

Pacientes com doenças graves, sem possibilidade de aguardar o tempo necessário para a identificação de um doador não aparentado, vêm sendo submetidos a transplantes haploidênticos, geralmente com as células-tronco de um de seus pais. Como a compatibilidade HLA é de apenas um haplótipo, ou seja, 50\% dos antígenos HLA, estes transplantes necessitam de esquemas imunossupressores intensos e específicos, sem os quais haveria doença do enxerto contra o hospedeiro fatal em todos os pacientes. O método mais difundido entre norte-americanos e europeus é a remoção dos linfócitos $\mathrm{T}$ do enxerto antes da infusão das célulastronco hematopoéticas. Sem os linfócitos T, a chance de doença do enxerto é bastante reduzida, mas as complicações infecciosas virais e fúngicas e a alta incidência de doença linfoproliferativa associada ao vírus Epstein-Barr passam a ser muito importantes. No contexto destes transplantes, é importante ainda optar pela incompatibilidade das células natural killer do doador e do paciente para protegê-los da recidiva da doença maligna. Outra estratégia recentemente desenvolvida, que permite a realização dos transplantes haploidênticos sem depleção de linfócitos $T$, reduzindo drasticamente o custo associado à manipulação das células in vitro e acelerando a recuperação imunológica, é o uso de ciclofosfamida após o transplante. ${ }^{36} \mathrm{Com}$ resultados preliminares bastante promissores, esta estratégia está atualmente em investigação em protocolo cooperativo multicêntrico no Blood and Marrow Transplant (BMT) Clinical Trials Network (CTN). (https://web.emmes.com/study/bmt/protocol/ 0603_protocol/0603_protocol.htm)

Parte da morbimortalidade associada aos transplantes com sangue de cordão é decorrente do longo período de tempo entre a infusão das células-tronco e a recuperação numérica e funcional da série leucocitária. Métodos que acelerem a pega das células-tronco hematopoéticas e a recuperação imunológica após os transplantes terão grande impacto nos resultados destes transplantes. Além de seleção e expansão de populações celulares específicas em laboratório, técnicas restritas a alguns poucos centros de altíssima tecnologia, está em estudo na Europa a infusão das células do cordão por via intramedular, ao invés de intravenosa, com resultados bastante promissores. ${ }^{37}$

É importante mantermos sempre em mente o objetivo de melhorar a chance de cura de nossas crianças. Um dos principais fatores ainda é o trabalho com pediatras, oncologistas e hematologistas para o diagnóstico precoce e o tratamento quimioterápico adequado. $\mathrm{O}$ estudo prospectivo da presença de doença residual mínima poderá ajudar a identificar crianças com LLA de alto risco e oferecer a elas transplante em uma fase mais precoce da doença, provavelmente com maior chance de cura. A agilidade no encaminhamento para o transplante, a redução do tempo necessário para a identificação de doadores e de espera pelo leito especializado também poderão beneficiar muitas crianças que hoje têm progressão da doença ou falecem por complicações enquanto esperam pelo transplante.

Um registro brasileiro de transplante, que está sendo organizado pela SBTMO, poderá ser fonte de importantes investigações clínicas em nosso país. Gostaríamos ainda de concluir com um convite a todos os interessados para trabalhar junto com o Comitê de Transplante de Medula Óssea em Pediatria Sobope/SBTMO no desenvolvimento de projetos e protocolos cooperativos. 


\section{Abstract}

Hematopoietic stem cell transplantation is a treatment option for a large number of children with malignant and non-malignant diseases. The objective of this article is to present the current status of hematopoietic stem cell transplantation in the treatment of malignant hematological diseases in pediatrics, including results in Brazil, and future perspectives. Rev. Bras. Hematol. Hemoter. 2009;31(Supl. 1):59-67.

Key words: Bone marrow transplantation; peripheral stem cell transplantation; pediatrics; leukemia.

\section{Referências Bibliográficas}

1. Schrauder A, von Stackelberg A, Schrappe M, Cornish J, Peters C; ALL-BFM Study Group; EBMT PD WP; I-BFM Study Group. Allogeneic hematopoietic SCT in children with ALL: current concepts of ongoing prospective SCT trials. Bone Marrow Transplant. 2008; 41 Suppl 2:S71-4.

2. Pasquini MC, Wang Z, Schneider L. Current use and outcome of hematopoietic stem cell transplantation: part I- CIBMTR Summary Slides, 2007. CIBMTR Newsletter [serial online]. 2007; 13(2):5-9.

3. Seber A, Castro HC, Borsato ML, Matsuo SE, Pires AL, Junior CGC, et al. Transplante de células-tronco hematopoiéticas em pediatria no Brasil. Rev. Bras. Hematol. Hemoter. 2008;30(supl 3):70-1.

4. Seber A, Castro HC, Borsato ML, Matsuo SE, Pires AL, Castro CG, et al. Transplante não-aparentado de células-tronco hematopoiéticas em pediatria. Rev. Bras. Hematol. Hemoter. 2008;30(supl 3):76-7.

5. Seber A, Castro HC, Borsato ML, Matsuo SE, Pires AL, Castro CG, et al. Transplante de células-tronco hematopoiéticas de sangue de cordão umbilical/ placenta em pediatria. Rev. Bras. Hematol. Hemoter. 2008;30(supl 3):70.

6. Castro HC, Borsato ML, Matsuo SE, Pires AL, Castro CG, Bonfim $\mathrm{C}$, et al. Transplante de células-tronco hematopoiéticas para o tratamento de leucemia linfóide aguda na infância. Rev. Bras. Hematol. Hemoter. 2008;30(supl 3):72.

7. Castro HC, Borsato ML, Matsuo SE, Pires AL, Castro CG, Bonfim $\mathrm{C}$, et al. Transplante de células-tronco hematopoiéticas para o tratamento de leucemia mielóide aguda na infância. Rev. Bras. Hematol. Hemoter. 2008; 30 (supl 3):72-3.

8. Seber A, Castro HC, Borsato ML, Matsuo SE, Pires AL, Bonfin C, et al. Transplante de células-tronco hematopoiéticas para o tratamento de síndrome mielodisplásica na infância. Rev. Bras. Hematol. Hemoter. 2008; 30 (supl 3):69.

9. Castro HC, Borsato ML, Matsuo SE, Pires AL, Castro CG, Bonfim $\mathrm{C}$, et al. Transplante de células-tronco hematopoiéticas para o tratamento de leucemia mielóide crônica na infância. Rev. Bras. Hematol. Hemoter. 2008;30 (supl 3):73.

10. Borsato ML, Castro HC, Bonfim C, Castro CG, Bouzas LF, Mauad $\mathrm{M}$, et al. Transplante de células tronco hematopoiéticas em linfomas pediátricos - análise multicêntrica. Rev. Bras. Hematol. Hemoter. 2008;30(supl 3):68.

11. Maia AT, van der Velden VH, Harrison CJ, Szczepanski T, Williams $\mathrm{MD}$, Griffiths MJ, et al. Prenatal origin of hyperdiploid acute lymphoblastic leukemia in identical twins. Leukemia;2003; 17(11):2202-6. 12.

12. Wiemels JL, Xiao Z, Buffler PA, Maia AT, Ma X, Dicks BM, et al. In utero origin of $\mathrm{t}(8 ; 21)$ AML1-ETO translocations in childhood acute myeloid leukemia. Blood. 2002;99(10):3801-5.
13. Gale KB, Ford AM, Repp R, Borkhardt A, Keller C, Eden OB, et al. Backtracking leukemia to birth: identification of clonotypic gene fusion sequences in neonatal blood spots. Proc Natl Acad Sci U S A. $1997 ; 94(25): 13950-4$.

14. Brenner MK, Rill DR, Moen RC, Krance RA, Heslop HE, Mirro J $\mathrm{Jr}$, et al. Gene marking and autologous bone marrow transplantation. Ann N Y Acad Sci. 1994;716:204-14.

15. Eapen M, Raetz E, Zhang MJ, Muehlenbein C, Devidas M, Abshire $\mathrm{T}$, et al; Childrens Oncology Group; Center for International Blood and Marrow Transplant Research. Outcomes after HLA-matched sibling transplantation or chemotherapy in children with B-precursor acute lymphoblastic leukemia in a second remission: a collaborative study of the Childrens Oncology Group and the Center for International Blood and Marrow Transplant Research. Blood. 2006;107(12):4961-7.

16. Schrappe M. Risk-adapted stratification and treatment of childhood acute lymphoblastic leukaemia. Radiat Prot Dosimetry. 2008;132 (2):130-3.

17. Rocha V, Cornish J, Sievers EL, Filipovich A, Locatelli F, Peters C, et al. Comparison of outcomes of unrelated bone marrow and umbilical cord blood transplants in children with acute leukemia. Blood. 2001;97(10):2962-71.

18. Locatelli F, Giorgiani G, Di-Cesare-Merlone A, Merli P, Sparta V, Moretta $\mathrm{F}$. The changing role of stem cell transplantation in childhood. Bone Marrow Transplant. 2008;41 Suppl 2:S3-7.

19. Petersdorf EW, Gooley TA, Anasetti C, Martin PJ, Smith AG, Mickelson EM, et al. Optimizing outcome after unrelated marrow transplantation by comprehensive matching of HLA class I and II alleles in the donor and recipient. Blood. 1998; 92(10):3515-20.

20. Petersdorf EW, Gooley T, Malkki M, Anasetti C, Martin P, Woolfrey A, et al. The biological significance of HLA-DP gene variation in haematopoietic cell transplantation. $\mathrm{Br} \mathrm{J}$ Haematol. 2001;112(4):988-94.

21. Petersdorf EW, Anasetti C, Martin PJ, Gooley T, Radich J, Malkki $\mathrm{M}$, et al. Limits of HLA mismatching in unrelated hematopoietic cell transplantation. Blood. 2004;104(9):2976-80.

22. Davies SM, DeFor TE, McGlave PB, Miller JS, Verfaillie CM, Wagner JE, et al. Equivalent outcomes in patients with chronic myelogenous leukemia after early transplantation of phenotypically matched bone marrow from related or unrelated donors. Am J Med. 2001;110(5):339-46.

23. Pasquini MC, Wang Z. Current use and outcome of hematopoietic stem cell transplantation: part II- CIBMTR summary slides, 2007. CIBMTR Newsletter [serial online]. 2008;14(1):6-13.

24. Reismüller B, Attarbaschi A, Peters C, Dworzak MN, Pötschger $\mathrm{U}$, Urban C, et al; Austrian Berlin-Frankfurt-Münster (BFM) Study Group. Long-term outcome of initially homogenously treated and relapsed childhood acute lymphoblastic leukaemia in Austria--a population-based report of the Austrian Berlin-Frankfurt-Münster (BFM) Study Group. Br J Haematol, 2009; 144(4): 559-70.

25. Borgmann A, von Stackelberg A, Hartmann R, Ebell W, Klingebiel T, Peters C, et al; Berlin-Frankfurt-Münster Relapse Study Group. Unrelated donor stem cell transplantation compared with chemotherapy for children with acute lymphoblastic leukemia in a second remission: a matched-pair analysis. Blood. 2003;101(10): 3835-9.

26. Bader P, Kreyenberg H, Henze GH, Eckert C, Reising M, Willasch A, et al; ALL-REZ BFM Study Group. Prognostic value of minimal residual disease quantification before allogeneic stemcell transplantation in relapsed childhood acute lymphoblastic leukemia: the ALL-REZ BFM Study Group. J Clin Oncol. 2009; 27(3):377-84. 
27. Klingebiel T, Reinhardt D, Bader P; EBMT Paediatric Diseases Working Party. Place of HSCT in treatment of childhood AML. Bone Marrow Transplant. 2008;42 Suppl 2:S7-9.

28. Woods WG, Neudorf S, Gold S, Sanders J, Buckley JD, Barnard DR, et al. Childrens Cancer Group. A comparison of allogeneic bone marrow transplantation, autologous bone marrow transplantation, and aggressive chemotherapy in children with acute myeloid leukemia in remission. Blood. 2001;97(1):56-62.

29. Shenoy S, Smith FO. Hematopoietic stem cell transplantation for childhood malignancies of myeloid origin. Bone Marrow Transplant.2008;41(2):141-8.

30. Klingebiel T, Reinhardt D, Bader P; EBMT Paediatric Diseases Working Party. Place of HSCT in treatment of childhood AML. Bone Marrow Transplant, 2008; 42 Suppl 2:S7-9.

31. Lopes, LF, Lorand-Metze I, Mendes WL, Seber A, Melo LN. Síndrome mielodisplásica na infância. Rev Bras Hematol Hemoter, 2006; 28 (3): 226-237.

32. Locatelli F, Nöllke P, Zecca M, Korthof E, Lanino E, Peters C, et $a l$; European Working Group on Childhood MDS; European Blood and Marrow Transplantation Group. Hematopoietic stem cell transplantation (HSCT) in children with juvenile myelomonocytic leukemia (JMML): results of the EWOG-MDS/EBMT trial. Blood. 2005;105(1):410-9.

33. Claviez A, Sureda A, Schmitz N. Haematopoietic SCT for children and adolescents with relapsed and refractory Hodgkins lymphoma. Bone Marrow Transplant. 2008;42 Suppl 2:S16-24.

34. Ladenstein R, Pearce R, Hartmann O, Patte C, Goldstone T, Philip T. High-dose chemotherapy with autologous bone marrow rescue in children with poor-risk Burkitts lymphoma: a report from the European Lymphoma Bone Marrow Transplantation Registry. Blood. 1997; 90(8):2921-30.

35. Pulsipher MA, Woolfrey A. Nonmyeloablative transplantation in children. Current status and future prospects. Hematol Oncol Clin North Am. 2001; 15(5):809-34, vii-viiii.

36. Luznik L, ODonnell PV, Symons HJ, Chen AR, Leffell MS, Zahurak $\mathrm{M}$, et al. HLA-haploidentical bone marrow transplantation for hematologic malignancies using nonmyeloablative conditioning and high-dose, posttransplantation cyclophosphamide. Biol Blood Marrow Transplant. 2008;14(6):641-50.

37. Frassoni F, Gualandi F, Podestà M, Raiola AM, Ibatici A, Piaggio G, et al. Direct intrabone transplant of unrelated cord-blood cells in acute leukaemia: a phase I/II study. Lancet Oncol. 2008;9.

Avaliação: O tema apresentado consta da pauta elaborada pelo editor, Professor Milton Artur Ruiz e coeditores deste suplemento, Professores Sergio Paulo Bydlowski e Adriana Seber.

Conflito de interesse: não declarado

Recebido: 19/02/2009

Aceito: $02 / 03 / 2009$ 